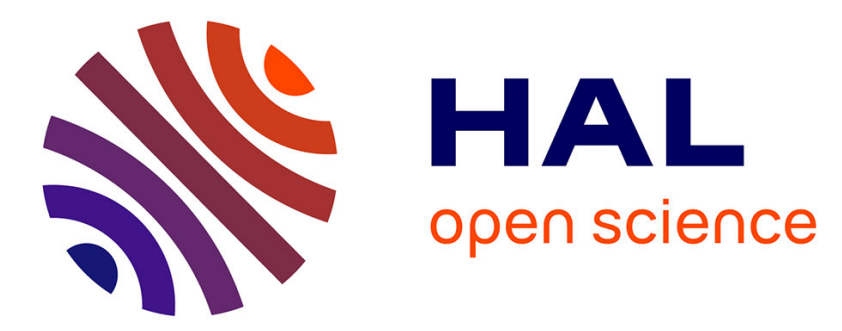

\title{
Developmental plasticity of the carotid chemoafferent pathway in rats that are hypoxic during the prenatal period.
}

Julie Peyronnet, Jean-Christophe Roux, Julie Mamet, David Perrin, Joël Lachuer, Jean-Marc Pequignot, Yvette Dalmaz

\section{To cite this version:}

Julie Peyronnet, Jean-Christophe Roux, Julie Mamet, David Perrin, Joël Lachuer, et al.. Developmental plasticity of the carotid chemoafferent pathway in rats that are hypoxic during the prenatal period.. European Journal of Neuroscience, 2007, 26 (10), pp.2865-2872. 10.1111/j.1460-9568.2007.05884.x . hal-00193015

\section{HAL Id: hal-00193015 https://hal.science/hal-00193015}

Submitted on 30 Nov 2007

HAL is a multi-disciplinary open access archive for the deposit and dissemination of scientific research documents, whether they are published or not. The documents may come from teaching and research institutions in France or abroad, or from public or private research centers.
L'archive ouverte pluridisciplinaire HAL, est destinée au dépôt et à la diffusion de documents scientifiques de niveau recherche, publiés ou non, émanant des établissements d'enseignement et de recherche français ou étrangers, des laboratoires publics ou privés. 


\title{
DEVELOPMENTAL PLASTICITY OF THE CAROTID CHEMOAFFERENT PATHWAY IN RATS THAT ARE HYPOXIC DURING THE PRENATAL PERIOD
}

\author{
J. Peyronnet $^{1,2}$, J.C. Roux ${ }^{1,3}$, J. Mamet ${ }^{1}$, D. Perrin ${ }^{1}$, J. Lachuer ${ }^{1}$, \\ J.M. Pequignot ${ }^{1}$ and Y. Dalmaz ${ }^{1}$
}

1 Université Lyon 1, Lyon, France; UMR CNRS 5123, Physiologie intégrative Cellulaire et Moléculaire, Villeurbanne, F-69622,

${ }^{2}$ Université Paul Cézanne Aix-Marseille III, Marseille, France ; UMR CNRS 6153, Physiologie Neurovégétative, Avenue Escadrille Normandie Niemen, cedex 13397,

${ }^{3}$ Université de la Méditerranée Aix-Marseille II, Marseille, France ; INSERM U491, Génétique médicale et développement, Faculté de Médecine de la Timone.

Key words: prenatal stress, maturation; catecholamines; chemoreflex, breathing control Running Title: Chemoafferent pathway plasticity and prenatal hypoxia

Correspondence

Dr. Julie Peyronnet-Roux

Laboratoire de Physiologie Neurovégétative, UMR CNRS 6153, Université Paul Cézanne Aix-Marseille III, Campus de St Jérôme, Av. Escadrille Normandie Niemen, CP 351-352, 13397 Marseille cedex 20.

E-mail, j.peyronnet-roux@univ-cezanne.fr 


\begin{abstract}
The chemoreflex pathway undergoes postnatal maturation, and perinatal environment plays a critical role in shaping respiratory control system. We investigated the role of prenatal hypoxia on the maturation of the chemoreflex neural circuits regulating ventilation in rat. Effects of hypoxia $\left(10 \% \mathrm{O}_{2}\right)$ from the $5^{\text {th }}$ to the $20^{\text {th }}$ day of gestation were studied on male offspring at birth and on postnatal days 3, 7, 21 and 68. Maturation of respiratory control system was assessed by in vivo tyrosine hydroxylase (TH) activity measurement in peripheral chemoreceptors (carotid bodies, petrosal ganglia), and in brainstem catecholaminergic cell groups $\left(\mathrm{A}_{2} \mathrm{C}_{2} \mathrm{C}\right.$ and $\mathrm{A}_{1} \mathrm{C}_{1}$ areas in the medulla, $A_{5}$ and $A_{6}$ areas in the pons). Resting ventilation and ventilatory response to hypoxia were evaluated as functional sequelae. In peripheral structures, prenatal hypoxia reduced $\mathrm{TH}$ activity within the first postnatal week and enhanced it later. In contrast, in central areas, prenatal hypoxia up-regulated $\mathrm{TH}$ activity within the first postnatal week and down-regulated it later. The in vivo $\mathrm{TH}$ activity impairment is therefore tissue-specific with an opposite effect on the peripheral and central neural circuits. A shift of the effect of prenatal hypoxia occurred between 1 and 3 weeks indicating a postnatal temporal effect of prenatal hypoxia. An important period in the development of the chemoafferent pathway occurred between the first and the third postnatal week. Functionally, prenatal hypoxia impaired resting ventilation and ventilatory response to hypoxia. The alterations of the catecholaminergic components of the chemoafferent pathway resulting from prenatal hypoxia might contribute to impair postnatal respiratory behaviour.
\end{abstract}




\section{INTRODUCTION}

Hypoxia during pregnancy represents a common problem during the foetal development, leading to numerous long-term adverse effects (Okubo \& Mortola, 1990; Nyakas et al., 1996; Peyronnet et al., 2000; 2002; Carroll, 2003a; Perrin et al., 2004).

In adult mammals, hypoxia increases ventilation through activation of the chemoafferent pathway. Hypoxemia is detected by peripheral chemoreceptors primarily located in the carotid bodies. This information is conveyed by chemoafferent fibres originating from the petrosal ganglion, and is integrated into discrete areas of the medulla oblongata containing catecholaminergic cell groups, i.e. mainly the nucleus tractus solitarius - caudal part - $\left(\mathrm{A}_{2} \mathrm{C}_{2} \mathrm{C}\right)$, the ventrolateral medulla $\left(\mathrm{A}_{1} \mathrm{C}_{1}\right)$, the ventrolateral pons $\left(A_{5}\right)$ and the locus coeruleus in the pons $\left(A_{6}\right)$ (Finley \& Katz, 1992; Guyenet et al., 1993; Bianchi et al., 1995). Both medullary areas are respectively associated to the dorsal and the ventral respiratory groups (Bianchi et al., 1995). These catecholaminergic brainstem areas participate in the control of breathing (Guyenet et al., 1993).

In rat neonates, the carotid body chemoreception pathway is immature. Maturation of the carotid body occurs over the first few postnatal weeks (Eden \& Hanson, 1987a; Hertzberg et al., 1990; Wang \& Bisgard 2005) and any change in environmental $\mathrm{O}_{2}$ modulates its development (Eden \& Hanson, 1987b; Hertzberg et al., 1992; Gauda et al., 2004; Bavis, 2005; Donnelly, 2005). Concerning catecholaminergic medullary areas, maturation of the nucleus tractus solitarius and ventrolateral medulla (Vincent \& Tell, 1999; White et al., 1994; Roux et al., 2003), of $\mathrm{A}_{5}$ (Di Pasquale et al., 1992) and of $A_{6}$ (Bezin et al., 1994) develops within the first two-three postnatal weeks. Neonatal (Slotkin et al., 1986) or prenatal (Nyakas et al., 1996) hypoxic exposure impairs the postnatal development and synaptogenesis of brain areas and we previously reported that prenatal hypoxia impairs the brainstem control of breathing of juvenile and adult rats (Peyronnet et al., 2000).

The purpose of this study was to evaluate the effect of prenatal hypoxia on the maturation of the chemoafferent pathway from birth to adulthood with a particular attention to the first week of life. Ontogenesis of the chemoafferent neural circuits following prenatal hypoxia was investigated using cellular and physiological tools. 
We assessed the effects of prenatal hypoxia $\left(10 \% \mathrm{O}_{2}\right.$ from day 5 to day 20 of gestation) on male offspring at birth (P0) and on postnatal (P) days 3, 7, 21 and 68. We determined the postnatal maturation of the respiratory control system by analysing the in vivo $\mathrm{TH}$ activity in the carotid body, the petrosal ganglion and the $\mathrm{A}_{2} \mathrm{C}_{2} \mathrm{C}, \mathrm{A}_{1} \mathrm{C}_{1}, \mathrm{~A}_{5}$ and $A_{6}$ brainstem cell groups. The physiological sequelae were evaluated on the development of the resting ventilation and the hypoxic ventilatory response. 


\section{MATERIALS AND METHODS}

\section{Hypoxia during pregnancy}

Twenty-four pregnant rats (Sprague-Dawley, IFFA CREDO, l'Arbresle, France) were exposed to hypoxia $\left(10 \% \mathrm{O}_{2}, 90 \% \mathrm{~N}_{2}\right)$ from day 5 to day 20 of gestation as previously described (Peyronnet et al., 2000). On day 20 of gestation, pregnant rats were housed individually and birth occurred in normoxia. At birth, all hypoxic pups were mixed and redistributed randomly to nursing females which had never been exposed to hypoxic conditions to avoid any possible effects of hypoxia on the quality of the milk and to minimise litter-to-litter variations. To ensure a common nutritional status, each nursing group contained 10-11 pups. Dams, which had been exposed to hypoxia, were no longer needed for this experiment. Hypoxic pups were identified according to their postnatal age and not according to their litters. Experiments were performed using only male pups in order to avoid gender parameter. All animals grew up in normoxia. These offspring constituted the prenatal hypoxic group (PH). The control group of rats was composed of pups delivered by normoxic mothers, whose gestation occurred under normoxic conditions in a similar Plexiglas chamber $\left(21 \% \mathrm{O}_{2}\right)$, mixed and redistributed randomly at birth to the normoxic mothers. All experiments were carried out according to the ethical principles laid down by the French (Ministère de l’Agriculture) and EU Council Directives for care of laboratory animals ( $\left.\mathrm{N}^{\circ} 02889\right)$.

\section{Plethysmography}

Ventilation was measured in awake unrestrained prenatal hypoxic and control rats at birth (P0), and on postnatal day 3 (P3), 7 (P7), 21 (P21) and (P68), using barometric plethysmography. According to the protocol described previously (Peyronnet et al., 2000). The volume of the Plexiglas chambers was $0.22 \mathrm{l}$ for the P0, P3 and P7 pups, $0.75 \mathrm{l}$ for the P21 offspring and $5.4 \mathrm{l}$ for the P68 rats, and calibration of the chambers was done before placing the animal in the box in order to avoid signal interferences between calibration and ventilation of the animal. Alternately, a control or a prenatal hypoxic rat was placed in the chamber for measurements of ventilation. Tidal volume $\left(\mathrm{V}_{\mathrm{T}}\right)$, respiratory frequency $(f)$ and minute ventilation $\left(\mathrm{V}_{\mathrm{E}}\right)$ were calculated from breathby-breath records over 30-50 consecutive cycles (around $30 \mathrm{~s}$ ) by computer analysis of 
the spirogram. $\mathrm{V}_{\mathrm{T}}$ was calculated by measuring the amplitude of the signal and not the area under the curve. $\mathrm{V}_{\mathrm{E}}, \mathrm{V}_{\mathrm{T}}$ and $f$ were respectively expressed in $\mathrm{ml} . \mathrm{min}^{-1}, \mathrm{ml}$ and min $^{-}$ ${ }^{1}$. All measurements in normoxia were performed in quadruplet. The mean of these 4 values was considered as the basal ventilation. The hypoxic test was then carried out by flushing the plethysmograph chamber with a mixture of $10 \% \mathrm{O}_{2}$ and $90 \% \mathrm{~N}_{2}$. After the $10 \% \mathrm{O}_{2}$ level was reached (within 10 seconds for the bigger volume) inside the chamber, the system was sealed to perform the measurements (1 min and 4 min after the beginning of hypoxia) of the hypoxic ventilatory response (HVR) involving 40 to 60 breath cycles in order to avoid $\mathrm{CO}_{2}$ accumulation. Between the tests performed at $1 \mathrm{~min}$ and $4 \mathrm{~min}$, the system was re-opened and the cage flushed with the hypoxic mixture. In order to collect correct data concerning $\mathrm{V}_{\mathrm{T}}$, we made sure all recordings were realised at an ambient temperature corresponding to thermoneutrality at each age group. The condition known as thermoneutrality is the range in ambient temperature over which body temperature is maintained with minimal metabolic effort. Furthermore, small variations of the ambient temperature lead to fluctuating values concerning $\mathrm{V}_{\mathrm{T}}$. This is especially true for small rodents. If necessary, the gas (air or hypoxia) was heated or cooled down before its entry in the plethysmograph. The set point of ambient temperature (thermoneutrality) was strictly the same for prenatal hypoxic rats and for controls. Finally, $\mathrm{V}_{\mathrm{T}}$ calculation remains an estimation and we do not interpret its absolute value. $\mathrm{V}_{\mathrm{T}}$ calculation is just used as a means to compare prenatal normoxic and hypoxic rats.

\section{Tissue dissection}

Neurochemical assays and ventilation were performed on separate animals at P0, P3, P7, P21 and P68 in order to discard possible neurochemical changes resulting from the exposure to the brief hypoxic challenge used for respiratory measurements. Control and prenatal hypoxic offspring were sacrificed by cooling at birth, (8-10h after birth) and on postnatal day 3, and by cervical dislocation after deep anaesthesia with pentobarbital i.p. on postnatal days 7, 21, 68 ( $n=10-12$ in each group and at each age). Excision of carotid bodies and petrosal ganglia was performed at each age under a dissection microscope. Petrosal ganglion and nodose ganglia were torn apart. Brains were rapidly removed from all animals. Each sample was frozen on dry ice and stored at 
$-80{ }^{\circ} \mathrm{C}$. As previously described (Soulier et al., 1997), after adjustment of the microtome blade to the plane containing the point where the pyramidal decussation appears, serial coronal slices of the brains were cut. Thickness of the slices was adapted according to the rat ages determined proportionally to the brain size (128 $\mu \mathrm{m}$ at birth, $160 \mu \mathrm{m}$ at P3, $192 \mu \mathrm{m}$ at P7, $384 \mu \mathrm{m}$ at P21, $480 \mu \mathrm{m}$ at P68), so that the appearance of the different structures in relation with the number of sections could be constant. Visualisation of the pyramidal decussation, the $\mathrm{VII}^{\text {th }}$ cranial nerve pair, the inferior olive, the IV ${ }^{\text {th }}$ ventricle, the cerebellum and the hippocampus was used as an anatomical point to confirm the relative position of the different areas. Moreover, we compared our different sections to Altman \& Bayer's (1995) developmental stereotaxic atlas. For the 21- and 68-day-old rats, cell groups were punched out according to the dissection procedure developed by Palkovits \& Brownstein (1988) and adapted to young animals (Roux et al., 2003).

\section{Neurochemistry}

The in vivo $\mathrm{TH}$ activity can be used as a marker of the rate of catecholamine synthesis (Carlsson et al., 1972). In vivo TH activity was estimated by measuring Ldihydroxyphenylalanine (L-DOPA) accumulation after inhibition of L-amino acid decarboxylase by NSD 1015 (3-hydroxybenzylhydrazine dichloride: Sigma, St Louis, USA). NSD 1015 was injected intraperitoneally (100 mg. $\mathrm{kg}^{-1}$ of body weight) $20 \mathrm{~min}$ before sacrifice. TH activity was expressed in picomoles of L-DOPA formed in $20 \mathrm{~min}$ and per pair of structures.

Total protein content can fluctuate unspecifically in physiological conditions, e.g., in response to circadian rhythms or chronic hypoxia (Poncet et al., 1994). Accordingly, the expression of the catecholamine activity per structure is more adequate than the expression of results per mg of protein in order to avoid artefactual variations of the catecholamine content and turnover following modifications of total protein levels in the structure.

\section{Biochemical analyses}

Structures were dissected out bilaterally and catecholamines were assayed on each pair of structures by high-performance liquid chromatography coupled with 
electrochemical detection. Tissues were disrupted by ultrasound in $100 \mu \mathrm{l} 0.4 \mathrm{M}$ (punches) or $0.1 \mathrm{M}$ (carotid body, petrosal ganglion) perchloric acid containing $2.7 \mathrm{mM}$ EDTA. In punch samples, the excess of perchloric acid was removed by addition of $8 \mu \mathrm{l}$ 6.4 M potassium formiate to the supernatant. Homogenates were centrifuged $(8,800 \mathrm{~g}, 5$ min) and a $20 \mu \mathrm{l}$ aliquot of the supernatant was injected directly into a reverse phase column (ODS-Hypersil, $5 \mathrm{~mm}, 150$ x $4.6 \mathrm{~mm}$, Shandon, Cheshire, UK) containing a mobile phase (27 mM citric acid, $50 \mathrm{mM}$ sodium acetate, $1 \mathrm{mM}$ EDTA- $\mathrm{Na}_{2}, 0.8 \mathrm{mM}$ sodium acetyl sulfate and $8 \%$ methanol). The flow rate was $1.2 \mathrm{ml} \mathrm{min}^{-1}$. L-DOPA was measured at $+0.72 \mathrm{~V}$ versus the $\mathrm{Ag}^{+} / \mathrm{AgCl}$ reference electrode (ELDEC 102, Chromatofield, Chateauneuf-les-Martigues, France). Detection limits, calculated by doubling the noise ratios and expressed in terms of picomoles of injected amounts, were less than 0.03 pmol for each compound and intra-assay coefficients were $0.2 \%$.

\section{Statistics}

Neurochemical data are expressed as means \pm S.E.M. For each structure, the effect of prenatal hypoxia was assessed using a two-way (prenatal hypoxia, age) analysis of variance (ANOVA) followed by Fisher's protected least square difference test. Ventilatory data are expressed as means \pm S.E.M. Because all studies were multivariate (prenatal hypoxia, age, time of hypoxic challenge), data were first subjected to global ANOVA. When a significant effect of treatment or interaction of treatment with age or hypoxic challenge was detected, lower order ANOVA was carried out to determine the time of hypoxic challenge or age of effect or interaction. In basal conditions, a twofactor ANOVA (prenatal hypoxia, age) was used to determine differences in ventilatory components between the prenatal and the control groups. The global response to hypoxia over 4 min was analysed using a three-factor ANOVA (prenatal hypoxia, age, hypoxic challenge). When interactions were significant, a post hoc test (Fisher's protected least square difference) was used to compare individual group. A $P$ value $\leq 0.05$ was considered to indicate statistical significance. 


\section{RESULTS}

\section{Prenatal hypoxia and body weight}

As we previously reported (Peyronnet et al., 2002, Perrin et al., 2004), body weight of the prenatal hypoxic offspring was significantly reduced at P0, P3 and P7 but was similar to that of controls at P21 and P68 (Fig.1).

\section{Prenatal hypoxia and postnatal maturation of the afferent $\mathrm{O}_{2}$-sensing pathway (carotid body, petrosal ganglion).}

Control rats: in the carotid body of control pups, the in vivo TH activity was high at birth (P0), it decreased during the first postnatal week compared to P0 (P3: 57\%; P7: -61\%) and increased thereafter to nearly reach the birth level at adulthood (Fig.2).

In the petrosal ganglion of control pups, the development of $\mathrm{TH}$ activity was mainly characterised by a peak at P7 compared to P0 (P7: $+163 \%)$ and a subsequent increase from the third week (Fig.2).

Prenatal hypoxic rats: in the carotid body of prenatal hypoxic rats, the developmental pattern of the TH activity was altered compared to matched-age controls, with a decrease on postnatal day $3(-25 \%)$ and $7(-41 \%)$ and an increase on postnatal day $68(+95 \%)$.

In the petrosal ganglion of prenatal hypoxic rats, the in vivo TH activity was decreased on postnatal day 7 (-40\%) and increased on postnatal day 21 (+35\%).

\section{Prenatal hypoxia and postnatal maturation of catecholaminergic brainstem cell groups}

The in vivo $\mathrm{TH}$ activity was measured in the $\mathrm{A}_{1} \mathrm{C}_{1}, \mathrm{~A}_{2} \mathrm{C}_{2} \mathrm{C}, \mathrm{A}_{5}$ and $\mathrm{A}_{6}$ cell groups in the brainstem from birth (P0) to postnatal day 68 (P68).

Control rats: in the $\mathrm{A}_{1} \mathrm{C}_{1}, \mathrm{~A}_{2} \mathrm{C}_{2} \mathrm{C}, \mathrm{A}_{5}$ and $\mathrm{A}_{6}$ cell groups of control rats, the postnatal development of the $\mathrm{TH}$ activity exhibited two marked increase in the $\mathrm{TH}$ activity (Fig.2). The first increase was detected at P3 compared to P0 $\left(\mathrm{A}_{2} \mathrm{C}_{2} \mathrm{C}\right.$ : $+306 \%$; $\left.\mathrm{A}_{1} \mathrm{C}_{1}:+227 ; \mathrm{A}_{5}:+190 \%\right)$ and at P21 compared to P7 $\left(\mathrm{A}_{2} \mathrm{C}_{2} \mathrm{C}:+584 \% ; \mathrm{A}_{1} \mathrm{C}_{1}:+715 ; \mathrm{A}_{5}\right.$ : $\left.+444 \% ; \mathrm{A}_{6}:+77 \%\right)$. A second increase occurred at P21 compared to P7 $\left(\mathrm{A}_{2} \mathrm{C}_{2} \mathrm{C}:+584 \%\right.$; $\left.\mathrm{A}_{1} \mathrm{C}_{1}:+715 \% ; \mathrm{A}_{5}:+444 \% ; \mathrm{A}_{6}:+77 \%\right)$. In adult rats (P68), $\mathrm{TH}$ activity was lowered 
compared to the preceding age (P21) in $\mathrm{A}_{2} \mathrm{C}_{2} \mathrm{C}(-55 \%), \mathrm{A}_{1} \mathrm{C}_{1}(-65 \%)$ and $\mathrm{A}_{5}(-70 \%)$ (Fig.2). Thus, at P21, brainstem areas exhibited an intense peak in the TH activity, except in $\mathrm{A}_{6}$.

Prenatal hypoxic rats: prenatal hypoxia altered the developmental pattern of the in vivo TH activity (Fig.2). Compared with the in vivo $\mathrm{TH}$ activity in matched-age control rats, this activity was increased in the brainstem areas during the first postnatal week (in $\mathrm{A}_{2} \mathrm{C}_{2} \mathrm{C}$ : $+72 \%$ and $+254 \%$ at $\mathrm{P} 0$ and $\mathrm{P} 3$ respectively, in $\mathrm{A}_{1} \mathrm{C}_{1}$ : $+174 \%$ and $+32 \%$ at $\mathrm{P} 3$ and $\mathrm{P} 7$ respectively, in $\mathrm{A}_{5}$ and $\mathrm{A}_{6}+64 \%$ and $+29 \%$ at $\mathrm{P} 3$ respectively). Later, $\mathrm{TH}$ activity was decreased in $\mathrm{A}_{2} \mathrm{C}_{2} \mathrm{C}$ (P21: -80\%; P68: -15\%), in $\mathrm{A}_{1} \mathrm{C}_{1}$ (P21: 70\%; P68:-16\%) and in $\mathrm{A}_{5}$ (P21:-70\%) cell groups (Fig.2).

The prenatal hypoxic exposure differently affects ontogenesis of the afferent $\mathrm{O}_{2}$ sensing pathway and of the catecholaminergic brainstem cell groups

Altogether, these data indicate that prenatal hypoxia induced, within the first week of life, a decrease in the TH activity in the carotid body and petrosal ganglia and an increase in the brainstem catecholaminergic cell groups $\left(\mathrm{A}_{1} \mathrm{C}_{1}, \mathrm{~A}_{2} \mathrm{C}_{2} \mathrm{C}, \mathrm{A}_{5}\right.$ and $\left.\mathrm{A}_{6}\right)$ (Fig.2). Later, we observed an increase in the TH activity in the carotid body and petrosal ganglion of prenatal hypoxic rats compared to control rats, whilst in the brainstem cell groups this activity was largely depressed compared to the control offspring. Two results have to be pointed out: i) for a given postnatal day, prenatal hypoxia elicited an inverse effect on the peripheral and central component, ii) for a given structure (carotid body, petrosal ganglion, $A_{2} C_{2} C, A_{1} C_{1}$ or $A_{5}$ ), the prenatal hypoxic effect was reversed between the first and the third weeks (Fig.2).

\section{Prenatal hypoxia impairs postnatal breathing}

Resting ventilation and hypoxic ventilatory response were measured in the control and prenatal hypoxic offspring at birth (P0) and on postnatal day 3, 7, 21 and 68 (Fig.3).

Resting ventilation: compared to age-matched controls, prenatal hypoxia elicited basal increase in ventilation on postnatal day 0 (+33\%), 3 (+38\%), 7 (+35\%) and 21 (+71\%) (Fig.3).The increase in the basal ventilation of the prenatal hypoxic animals was mainly due to a higher frequency for the 0 - 3- and 7-day-old pups $(+24 \%,+26 \%,+13 \%$ respectively) and to a higher tidal volume for the 21-day-old rats (+96\%). 
Hypoxic ventilatory response; control rat: compared to respective basal values, hypoxic ventilatory response on the first minute of hypoxic exposure was characterised by a significant increase in the minute ventilation (P0: $+63 \%$; P3: $+49 \%$; P7: $+43 \%$; P21: +122\%; P68: +51\%) (Fig.3), mainly due to an increase in the frequency. On the fourth minute of hypoxia the minute ventilation returned within the basal values for the 0-, 3- and 7-day-old offspring, reflecting the typical newborn biphasic response, and remained significantly increased for the 21 - and 68 -day-old rats $(+137 \%$ and $+83 \%$ respectively) (Fig.3).

Hypoxic ventilatory response; prenatal hypoxic rats: compared to respective basal values, the minute ventilation was increased on the first minute of hypoxia, except for the 7-day-old offspring, (P0: +46\%; P3: +46\%; P21: +134\%; P68: +68\%) (Fig.3), mainly due to an increased frequency. Four minutes of hypoxic challenge sustained the initial increase in the minute ventilation compared to basal values (P0:+46\%; P3: $+46 \%$, P21: 132\%; P68: +78\%). Therefore, the biphasic newborn response observed in control rats within the first week of age was not evidenced in the prenatal hypoxic pups. At the end of the hypoxic exposure, the minute ventilation set at a higher level in the 3-, 7- and 21-day-old prenatal hypoxic rats compared to the matched-age control animals $(+51 \%$, $+61 \%$ and $+67 \%$ respectively), due to an increased frequency on P3 and an increased tidal volume on P7 and P21. Most of the altered ventilatory parameters were resolved at P68 (Fig.3).

\section{DISCUSSION}

The present study shows that a two-week prenatal hypoxic exposure alters the maturation of the afferent $\mathrm{O}_{2}$-sensing pathway (carotid body and petrosal ganglion) and the brainstem catecholaminergic cell groups $\left(\mathrm{A}_{2} \mathrm{C}_{2} \mathrm{C}, \mathrm{A}_{1} \mathrm{C}_{1}, \mathrm{~A}_{5}\right.$ et $\mathrm{A}_{6}$ cell groups) involved in the regulation of breathing. Because of the postnatal maturation of the chemoafferent pathway, this study focused on the first three weeks of life. To the best of our knowledge, this is the first study combining a longitudinal analysis of neurochemical and physiological events related to breathing in response to a common prenatal environment. Our data show that, after prenatal hypoxia, $i$ ) the developmental change of the in vivo TH activity is tissue-specific with an opposite effect on the afferent $\mathrm{O}_{2}$-sensing pathway and on the brainstem catecholaminergic cell groups, ii) a 
shift of the effect of prenatal hypoxia occurs between 1 and 3 weeks indicating that the period between the first and the third postnatal weeks is important for the development of the chemoafferent pathway, iii) ventilation is increased in normoxia and in hypoxia and there is no evidence for the biphasic response to hypoxia.

\section{Experimental comments}

In the present study, only males were retained to avoid female hormonal effect on ventilation (Joseph et al., 2000; Bavis et al., 2004). The duration of exposure to hypoxia was quite long (E5-E20) compared to most of the studies in rats referring to short perinatal hypoxia/ischemia. This model of mild and long-term prenatal hypoxia mimics pathological hypoxic situations in pregnant women. Although the degree of foetal hypoxemia caused by exposure of the pregnant rats to hypoxia cannot be evaluated, we previously showed that these experimental conditions increased the maternal haematocrit (75 $\pm 6 \%$ vs. $51 \pm 1 \%$ ) and the expression of HIF-1 $\alpha$ in the foetal brain, which indicates a characteristic adaptive response to hypoxemia (Royer et al., 2000). Furthermore, in sheep and goats, a prenatal hypoxic stress, with a similar level of oxygen tension, was able to decrease foetal $\mathrm{PaO}_{2}$ and to stimulate the carotid chemoreflex pathway (Nitsos \& Walker, 1999).

Ventilation was evaluated using whole body plethysmography. The accuracy of $\mathrm{V}_{\mathrm{T}}$ calculation based on whole body plethysmography data has been questioned, especially in newborns (Enhorning et al., 1998). The absolute $\mathrm{V}_{\mathrm{T}}$ and $\mathrm{V}_{\mathrm{E}}$ values should be viewed with caution, but they were appropriately used to compare control and prenatal hypoxic data resulting from the same experimental design. Neurochemical assays and ventilation were performed on separate animals at P0, P3, P7, P21 and P68 in order to discard possible changes in the neural pathway activity resulting from the exposure to the brief hypoxic challenge used for respiratory measurements.

\section{Ontogenesis of the in vivo TH activity of the chemoreflex pathway in normoxia}

The data indicate that the pattern of postnatal development of the $\mathrm{TH}$ activity within structures in the chemoafferent pathway is not homogeneous and undergoes changes according to the tissues. 
In carotid bodies of control animals, the present study reveals a decline in $\mathrm{TH}$ activity within the first postnatal week. Among the numerous neurotransmitters present in the neurosecretory type I cells of the carotid body, catecholamines and especially dopamine has received the most attention (Gonzalez et al., 1994; Bairam \& Carroll, 2005). The carotid body in the foetus is well adapted to the low $\mathrm{O}_{2}$ tension in utero. Postnatal maturation of the carotid body is dependent on environmental oxygen supply (Carroll, 2003b; Donnelly, 2005; Wang \& Bisgard, 2005). At birth, when suddenly exposed to a relative high $\mathrm{O}_{2}$ level, the carotid body changes its dopamine metabolism by decreasing the dopamine turnover and the mRNA encoding TH (Hertzberg et al., 1990; Bairam \& Carroll 2005). This neurochemical resetting is partly involved in the postnatal resetting of carotid body $\mathrm{O}_{2}$ sensitivity (Holgert et al., 1995). Our data on the developmental decrease in the $\mathrm{TH}$ activity extended previous results obtained on dopamine turnover and TH expression, and strengthened the evidence for a decline of the dopamine metabolism within the first postnatal week.

In the control petrosal ganglion containing the cell bodies of the afferent neurones, the in vivo $\mathrm{TH}$ activity increased within the first week. The data indicate that the developmental pattern in this ganglion is different from that observed in the carotid body. We propose that the catecholamine contents in the petrosal ganglion could be non-limiting in order to convey the carotid body inputs. Indeed, it has been earlier shown that developmental changes in cell characteristics of the petrosal ganglion are small and are unlikely to account for the developmental increase in chemoreceptor responsiveness with age (Donnelly, 1999).

In central areas, the development of TH activity is characterised by two different increases, the first occurring between P0-P3, the second between P7-P21. Enhanced TH activity at P3 could result from the environmental changes induced by the transition from foetal to extra-uterine life (Lagercrantz et al., 1992). Increase at P21 extended previous data obtained in the whole brainstem (Coyle \& Axelrod, 1972) and appeared to be specific to these catecholaminergic brainstem areas (Perrin et al., 2004). Maturation of the brainstem sites takes between two to four weeks to complete (White et al., 1994; Vincent \& Tell, 1999). The second-third week is crucial for the developing rat brain because of changes in the energetic metabolism associated with the weaning period (Clark et al., 1993). Within this period numerous neuromodulators in the brainstem 
exhibit changes in their level of expression (Wong-Riley \& Liu, 2005). This transient enhancement of the TH activity in most of the catecholaminergic brainstem nuclei at P21 could result from the activation of quiescent cells expressing the TH phenotype (Bezin et al., 1994) in relation with the energetic needs. It might also be related to the maturation of the cardio-respiratory control (Roux et al., 2003; Wong-Riley \& Liu, 2005).

\section{Prenatal hypoxia alters the ontogenesis of the TH activity of the chemoafferent pathway}

In the carotid body, prenatal hypoxia amplified the developmental pattern of the TH activity changes reported in controls. Prenatal hypoxia enhanced the downregulation within the first postnatal week and increased the up-regulation in adulthood. It has previously been shown that a postnatal hypoxic environment blunted the dopamine metabolism decline (Hertzberg et al., 1992). Since prenatal hypoxia enhanced the difference between the foetal and the postnatal oxygen tension (Royer et al., 2000), we can postulate that this higher relative hyperoxia could be responsible for the higher adjustment and decline of the catecholamine metabolism. In the petrosal ganglion, as in the carotid body, prenatal hypoxia down-regulated the TH activity at P7 and upregulated it later (P21), thus indicating that prenatal hypoxia has the same effect on the $\mathrm{TH}$ activity in the cell bodies and in the peripheral sensitive nerve terminals.

Prenatal hypoxic exposure affects ontogenesis of the afferent $\mathrm{O}_{2}$-sensing pathway and of the brainstem catecholaminergic cell groups differently. In the brainstem cell groups, it amplified the increase in the TH activity observed in the control group at P3 and blunted the surge evidenced in the controls at P21, except in $A_{6}$. Thus, the brainstem cell groups exhibited a TH activity which was up-regulated within the first postnatal week and down-regulated thereafter. At P3 and P21, the opposite effect of prenatal hypoxia on the peripheral and central components is conceivable since dopamine in the carotid body and noradrenaline in the brainstem are both inhibitory neuromodulators of breathing (Gonzalez et al., 1994). It strongly suggests brainstem adjustment and compensation in response to the variation of the peripheral inputs. Consistent with this proposal, the lack of peripheral inputs from the carotid bodies following carotid sinus nerve transection affects $\mathrm{TH}$ activity in medullary areas with a 
down-regulation and a subsequent up-regulation (Roux et al., 2000). Carotid bodies (Donnelly \& Haddad, 1990) and BDNF/GDNF afferent inputs of the afferent fibres (Katz, 2005) are essential for regulating the development of brainstem respiratory network. Altogether, these data suggest that variation of the peripheral inputs induces a central compensatory action/reaction and is involved in the remodelling of central catecholaminergic areas during development.

\section{Prenatal hypoxia reveals an important period for maturation of the chemoafferent pathway}

A two-week prenatal hypoxia revealed an important period for the postnatal development of the chemoafferent pathway. A shift of the effect of prenatal hypoxia occurred between 1 and 3 weeks. Before and after this stage, the modifications of the $\mathrm{TH}$ activity were reversed in both peripheral and central structures (down-regulation and subsequent up-regulation in carotid body and petrosal ganglion, up-regulation and subsequent down-regulation in $\mathrm{A}_{2} \mathrm{C}_{2} \mathrm{C}, \mathrm{A}_{1} \mathrm{C}_{1}$ or $\mathrm{A}_{5}$ ). Prenatal hypoxia strengthened the notion of an important period that we showed with $\mathrm{TH}$ measurement in central areas of controls and extended it to the chemoafferent pathway.

Chronic hyperoxia (Bavis et al., 2002) or acute hypoxic challenge (Liu et al., 2006) also revealed a sensitive period in the breathing and neural control mechanisms occurring around the second postnatal week.

This important period for the development of the chemoafferent pathway, evidenced in this study after prenatal hypoxia, can be related to several morphological and electrophysiological phases of synaptic maturation occurring in the nucleus tractus solitarius and ventrolateral medulla (White et al., 1994; Liu \& Wong-Riley, 2003). A developmental imbalance between neurochemical excitatory and inhibitory systems in the brainstem occurs at the end of the second postnatal week (Wong-Riley \& Liu, 2005). Our study also evidenced a temporal imbalance of the involvement of the catecholaminergic structures related to the chemoafferent pathway.

\section{Prenatal hypoxia alters postnatal breathing}

Data of the prenatal hypoxic group of animals showed increased ventilation in normoxia as in response to a hypoxic test but no biphasic response to hypoxia. 
Ventilation undergoes significant maturational changes in the postnatal period (Liu et al., 2006) and perinatal environment plays a critical role in shaping ventilation and respiratory control (Bavis et al., 2002, 2004, 2005; Carroll, 2003a; Mortola, 2004; Donnelly, 2005). The increased basal ventilation in normoxia and the lack of the biphasic response to hypoxia of offspring prenatally exposed to hypoxia might represent a shift in the balance of the excitatory action of carotid body chemoreceptors (Lahiri et al., 1978) and inhibitory effect of central pathways (Eden \& Hanson, 1987ab; Fung et al., 1996; Bissonnette, 2000). Whilst the role of dopamine in the carotid body function is still questioned in vivo (Gonzalez et al., 1994; Donnelly, 2005), the carotid body exerts a vital influence when the medullary control is immature and then switch from a vital to a regulatory role after complete maturation of the central autonomic areas.

For small animals, important factors influencing the response to hypoxia are body weight and metabolic rate (Mortola, 2003, 2004). We previously reported that these prenatal 7-day-old hypoxic pups did not exhibit the reduced oxygen consumption observed in controls in response to a postnatal hypoxic exposure (Peyronnet et al., 2000). We cannot exclude that the lack of the decline in ventilation over the course of the hypoxic challenge observed in the prenatal hypoxic offspring until P7 might not partly result from their lack of hypoxic hypometabolism (Peyronnet et al., 2000).

Among the numerous neuromodulators involved in breathing and the hypoxic ventilatory response (Bianchi et al., 1995), the role of monoamines in the respiratory control is established (Guyenet et al., 1993). The altered developmental evolution of the TH activity after prenatal hypoxia can be considered as a neuronal marker of the central reorganisation involved in this new ventilatory pattern. In conclusion, by using a double approach, both cellular (TH activity) and functional (ventilation), this study is the first to demonstrate that prenatal hypoxia alters the activity of the chemoafferent pathway, from birth, with lasting postnatal cellular and functional sequelae.

\section{Implications for humans}

In humans, several pathophysiological situations are associated with a deficit in oxygen supply for the foetus, such as maternal anaemia, hypertension, reduced placenta 
size, pre-eclampsia, smoking, reduced oxygen supply in high altitude. Our data may be relevant to understand clinical syndromes during the neonatal period. In the Sudden Infant Death Syndrome (SIDS), impaired pattern in respiratory activity (Gordon et al., 1984; Schechtman et al., 1990), disappearance of catecholaminergic markers in $\mathrm{A}_{1} \mathrm{C}_{1} / \mathrm{A}_{2} \mathrm{C}_{2} \mathrm{C}$ (Obonai et al., 1998) and activation of the dopamine metabolism in carotid bodies (Perrin et al., 1984) have been reported. Carotid chemoreflex plays a critical role in the survival of newborns by protecting them against prolonged apnoeas (Donnelly \& Haddad, 1990) and failure of the development of functional chemoreceptors (Gauda et al., 2004; Cohen \& Katz-Salamon, 2005) has been evoked in breathing dysfunction in infants. The present prenatal hypoxic protocol in rats appears particularly relevant in order to better understand the neurochemical pathogenesis of these developmental disorders.

\section{Acknowledgements}

This work was supported by the CNRS, the University Claude Bernard Lyon 1, and the Région Rhone-Alpes (France). The skilful technical assistance of J. Péquignot was greatly appreciated.

\section{Abbreviations}

ANOVA, analysis of variance; $C B$, carotid body; $f$, frequency; min, minute; HVR, hypoxic ventilatory response; PG, petrosal ganglion; S.E.M., standard error of the mean; $\mathrm{TH}$, tyrosine hydroxylase; $\mathrm{V}_{\mathrm{E}}$, minute ventilation; $\mathrm{V}_{\mathrm{T}}$, tidal volume. 


\section{REFERENCES}

Altman, J. \& Bayer, S.A. (1995) Atlas of prenatal rat brain development. CRC Press, Boca Raton Ann Arbor, London, Tokyo.

Bairam, A. \& Carroll, J.L. (2005) Neurotransmitters in carotid body development. Resp. Physiol. Neurobiol.,149, 217-232.

Bavis, R.W., Olson, E.B. \& Mitchell, G.S. (2002) Critical developmental period for hyperoxia-induced blunting of hypoxic phrenic responses in rats. J. Appl. Physiol., 92, 1013-1018.

Bavis, R.W., Olson, E.B., Vidruck, E.H., Fuller, D.D. \& Mitchell, G.S. (2004) Developmental plasticity of the hypoxic ventilatory response in rats induced by neonatal hypoxia. J. Physiol., 557, 645-660.

Bavis, R.W. (2005) Developmental plasticity of the hypoxic ventilatory response after perinatal hyperoxia or hypoxia. Resp. Physiol. Neurobiol., 149, 287-299.

Bezin, L., Marcel, D., Debure, L.I., Ginovart, N., Rousset, C., Pujol, J.F. \& Weissmann, D. (1994) Postnatal development of the tyrosine hydroxylase-containing cell population within the rat locus coeruleus: topological organisation and phenotypic plasticity. J. Neurosci., 14, 7486-7501.

Bianchi, A.L., Denavit-Saubie, M. \& Champagnat, J. (1995) Central control of breathing in mammals: neuronal circuitry, membrane properties, and neurotransmitters. Physiol. Rev., 75, 1-45.

Bissonnette, J.M. (2000) Mechanisms regulating hypoxic respiratory depression during fetal and postnatal life. Am. J. Physiol. Regul. Integr. Comp. Physiol., 278, 149-159.

Carlsson, A., Davis, J.N., Kehr, W., Lindqvist, M. \& Atack, C.V. (1972) Simultaneous measurement of tyrosine and tryptophan hydroxylase activities in brain in vivo using an inhibitor of the aromatic amino acid decarboxylase. Naunym-Schmied. Arch. Pharmacol., 275, 153-168.

Carroll, J.L. (2003a) Developmental plasticity in respiratory control. J. Appl. Physiol., 94, 375-389.

Carroll, J.L. (2003b) Postnatal maturation of the carotid $\mathrm{O}_{2}$ sensitivity at the cellular level. In Lahiri, S., Semenza, G.L. \& Prabakhar, N.R. (eds), Lung Biology in Health and Disease, Oxygen Sensing Responses and Adaptation to Hypoxia. Marcell Dekker, New York, Basel, Vol. 175, pp.251-271. 
Clark, J.B., Bates, T.E., Cullingford, T. \& Land, J.M. (1993) Development of enzymes of energy metabolism in the neonatal mammalian brain. Dev Neurosci., 15, 174-180.

Cohen, G. \& Katz-Salamon, M. (2005) Development of chemoreceptors in infants. Resp. Physiol. Neurobiol.,149, 233-242.

Coyle, J.T. \& Axelrod, J. (1972) Tyrosine hydroxylase in rat brain: developmental characteristics. J. Neurochem., 19, 1117-1123.

Di Pasquale, E., Morin, D., Monteau, R. \& Hilaire, G (1992) Serotonergic modulation of the respiratory rhythm generator at birth: an in vitro study in the rat. Neurosci. Lett., 143, 91-95.

Donnelly, D.F. \& Haddad, G.G. (1990) Prolonged apnea and impaired survival in piglets after sinus and aortic nerve section. J. Appl. Physiol., 68, 1048-1052.

Donnelly, D.F. (1999) Developmental changes in membrane properties of chemoreceptor afferent neurons of the rat petrosal ganglia. J. Neurophysiol., 82, 209-215.

Donnelly, D.F. (2005) Development of carotid body/petrosal ganglion response to hypoxia. Resp. Physiol. Neurobiol., 149,191-199.

Eden, G.J. \& Hanson, M.A. (1987a) Maturation of the respiratory response to acute hypoxia in the newborn rat. J. Physiol., 392, 1-9.

Eden, G.J. \& Hanson, M.A. (1987b) Effects of chronic hypoxia from birth on the ventilatory response to acute hypoxia in the newborn rat. J. Physiol., 392, 11-19.

Enhorning, G., van Schaik, S., Lundgren, C. \& Vargas, I. (1998) Whole-body plethysmography, does it measure tidal volume of small animals. Can. J. Physiol. Pharmacol., 76, 937-944.

Finley, J.C. \& Katz, D.M. (1992) The central organization of carotid body afferent projections to the brainstem of the rat. Brain Res., 572, 108-116.

Fung, M.L., Wang, W., Darnall, R.A. \& St John, W.M. (1996) Characterization of ventilatory responses to hypoxia in neonatal rats. Respir. Physiol., 103, 57-66.

Gauda, E.B., McLemore, G.L., Tolosa, J. Marston-Nelson J. \& Kwak D. (2004) Maturation of peripheral arterial chemoreceptors in relation to neonatal apnoea. Seminars in Neonatalogy, 9, 181-194. 
Gonzalez, C., Almaraz, L., Obeso, A. \& Rigual, R. (1994) Carotid body chemoreceptors: from natural stimuli to sensory discharges. Physiol. Rev., 74, 829898.

Gordon, D., Cohen, R.J., Kelly, D., Akselrod, S. \& Shannon, D.C. (1984) Sudden infant death syndrome: abnormalities in short term fluctuations in heart rate and respiratory activity. Pediatr. Res., 18, 921-926.

Guyenet, P.G., Koshiya, N., Huangfu, D., Verberne, A.J. \& Riley, T.A. (1993) Central respiratory control of A5 and A6 pontine noradrenergic neurons. Am. J. Physiol., 264, R1035-R1044.

Hertzberg, T., Hellström, S., Lagercrantz, H. \& Pequignot, J.M. (1990) Development of the arterial chemoreflex and turnover of the carotid body catecholamines in the newborn rats. J. Physiol., 425, 211-225.

Hertzberg, T., Hellström, S., Holgert, H., Lagercrantz, H. \& Pequignot, J.M. (1992) Ventilatory response to hyperoxia in newborn rats born in hypoxia - possible relationship to carotid body dopamine. J. Physiol., 456, 645-654.

Holgert, H., Hokfelt, T., Hertzberg, T. \& Lagercrantz, H. (1995) Functional and developmental studies of the peripheral arterial chemoreceptors in rat: effects of nicotine and possible relation to sudden infant death syndrome. Proc. Natl. Acad. Sci. U S A, 92, 7575-7579.

Joseph, V., Soliz, J., Pequignot, J., Sempore, B., Cottet-Emard, J.M., Dalmaz, Y., Favier, R., Spielvogel, H. \& Pequignot, J.M. (2000) Gender differentiation of the chemoreflex during growth at high altitude: functional and neurochemical studies. Am. J. Physiol. Regulatory Integrative Comp. Physiol., 278, 806-816.

Katz, D.M. (2005) Regulation of respiratory neuron development by neurotrophic and transcriptional signaling mechanisms. Resp. Physiol. Neurobiol., 149, 99-109.

Lagercrantz, H., Pequignot, J., Pequignot, J.M. \& Peyrin, L. (1992) The first breaths of air stimulate noradrenaline turnover in the brain of the newborn rat. Acta Physiol. Scand., 144, 433-438.

Lahiri, S., Mokashi, A., Delaney, R.G. \& Fishman, A.P. (1978) Arterial PO2 and PCO2 stimulus threshold for carotid chemoreceptors and breathing. Respir. Physiol., 34, 359-375. 
Liu, Q. \& Wong-Riley, M.T.T (2003) Postnatal changes in cytochrome oxidase expressions in brain stem nuclei of rats: implications for sensitive periods. J. Appl. Physiol., 95, 2285-2291.

Liu, Q., Lowry T.F. \& Wong-Riley, M.T.T. (2006) Postanal changes in ventilation during normoxia and acute hypoxia in the rat: implication for a sensitive period. $J$. Physiol., 577, 957-970.

Mortola, J.P. (2003) Metabolic and ventilatory interaction in the newborn. In: Massaro, D., Massaro, G., Chambon, P. (Eds), Lung development and regeneration. Marcel Dekker, New York, NY, 20, 525-571.

Mortola, J.P. (2004) Implications of hypoxic hypometabolism during mammalian ontogenesis. Resp. Physiol. Neurobiol., 141, 345-356.

Nitsos I, Walker DW. (1999) The distribution of FOS-immunoreactive neurons in the brainstem, midbrain and diencephalon of fetal sheep in response to acute hypoxia in mid and late gestation. Brain Res Dev Brain Res., 114, 9-26.

Nyakas, C., Buwalda, B. \& Luiten, P.G. (1996) Hypoxia and brain development. Prog. Neurobiol., 49, 1-51.

Obonai, T., Yasuhara, M., Nakamura, T. \& Takashima, S. (1998) Catecholamine neurons alteration in the brainstem of sudden infant death syndrome victims. Pediatrics, 101, 285-288.

Okubo, S. \& Mortola, J.P. (1990) Control of ventilation in adult rats hypoxic in the neonatal period. Am. J. Physiol., 259, R836-R841.

Palkovits, M. \& Brownstein, M.J. (1988) Maps and guide to microdissection of the rat brain. Elsevier, Amsterdam.

Perrin, D.G., Cutz, E., Becker, L.E., Bryan, A.C., Madapallimatum, A. \& Sole, M.J. (1984) Sudden infant death syndrome: increased carotid-body dopamine and noradrenaline content. Lancet, 2, 535-537.

Perrin, D., Mamet, J., Scarna, H., Roux, J.C., Berod, A. \& Dalmaz, Y. (2004) Longterm prenatal hypoxia alters maturation of brain catecholaminergic systems and motor behavior in rats. Synapse, 54, 92-101.

Peyronnet, J., Roux, J.C., Geloen, A., Tang, L.Q., Pequignot, J.M., Lagercrantz, H. \& Dalmaz, Y. (2000) Prenatal hypoxia impairs the postnatal development of neural and functional chemoafferent pathway in rat. J. Physiol., 524, 525-537. 
Peyronnet, J., Dalmaz, Y., Ehrstrom, M., Mamet, J., Roux, J.C., Pequignot, J.M., Thoren, H.P. \& Lagercrantz, H. (2002) Long-lasting adverse effects of prenatal hypoxia on developing autonomic nervous system and cardiovascular parameters in rats. Pflugers Arch., 443, 858-865.

Poncet, L., Denoroy, L., Dalmaz, Y., Pequignot, J.M. \& Jouvet, M. (1994) Chronic hypoxia affects peripheral and central vasoactive intestinal peptide-like immunoreactivity in the rat. Neurosci. Lett., 176, 1-4.

Roux, J.C., Peyronnet, J., Pascual, O., Dalmaz, Y. \& Pequignot, J.M. (2000) Ventilatory and central neurochemical reorganisation of $\mathrm{O}_{2}$ chemoreflex after carotid sinus nerve transection in rat. J. Physiol., 522, 493-501.

Roux, J.C., Mamet, J., Perrin, D., Peyronnet, J., Royer, C., Cottet-Emard, J.M., Pequignot, J.M. \& Dalmaz, Y. (2003) Neurochemical development of the brainstem catecholaminergic cell groups in rat. J. Neural Transm., 110, 51-65.

Royer, C., Lachuer, J., Crouzoulon, G., Roux, J., Peyronnet, J., Mamet, J., Pequignot, J. \& Dalmaz, Y. (2000) Effects of gestational hypoxia on mRNA levels of Glut3 and Glut4 transporters, hypoxia inducible factor-1 and thyroid hormone receptors in developing rat brain. Brain Res., 856, 119-128.

Schechtman, V.L., Harper, R.M., Kluge, K.A., Wilson, A.J. \& Southall, D.P. (1990) Correlations between cardiorespiratory measures in normal infants and victims of sudden infant death syndrome. Sleep, 13, 304-317.

Slotkin, T.A., Cowdery, T.S., Orband, L., Pachman, S. \& Whitmore, W.L. (1986) Effects of neonatal hypoxia on brain development in the rat: immediate and longterm biochemical alterations in discrete regions. Brain Res., 374, 63-74.

Soulier, V., Dalmaz, Y., Cottet-Emard, J.M., Lagercrantz, H. \& Pequignot, J.M. (1997) Long-term influence of neonatal hypoxia on catecholamine activity in carotid bodies and brainstem cell groups of the rat. J. Physiol., 498, 523-530.

Vincent, A. \& Tell, F. (1999) Postnatal development of rat nucleus tractus solitarius neurons: morphological and electrophysiological evidence. Neuroscience, 93, 293305.

Wang, Z.Y. \& Bisgard, G.E. (2005) Postnatal growth of the carotid body. Respir. Physiol. Neurobiol., 149, 181-190. 
White, L.D., Lawson, E.E. \& Millhorn, D.E. (1994) Ontogeny of the $\mathrm{O}_{2}$-sensitive pathway in medulla oblongata of postnatal rat. Respir. Physiol., 98, 123-135.

Wong-Riley, M.T.T. \& Liu, Q. (2005) Neurochemical development of brainstem nuclei involved in the control respiration. Respir. Physiol. Neurobiol., 149, 83-98. 


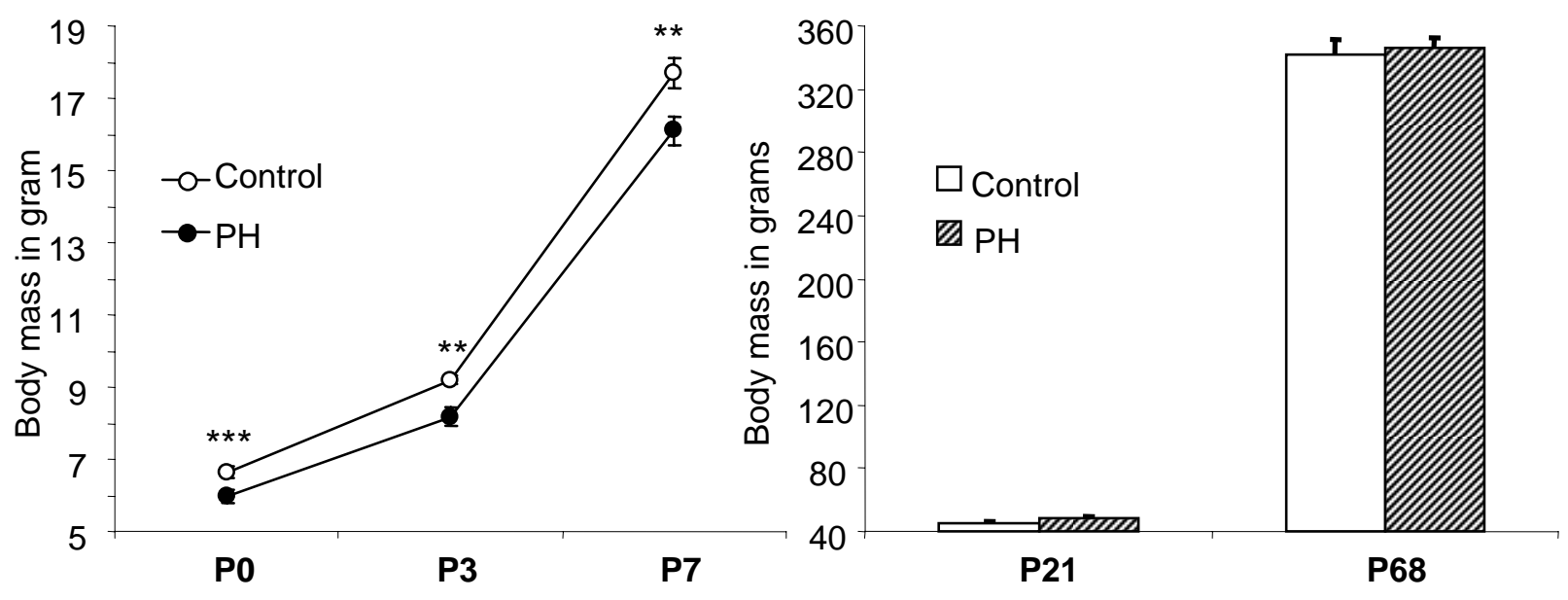

FIG.1. Long term effects of the prenatal hypoxic treatment on the body weight. Data are expressed as means \pm S.E.M. at birth (P0) postnatal day 3, 7, 21 and 68. Significant differences between normoxic (Control) and prenatal hypoxic $(\mathrm{PH})$ groups of rats $(* * P$ $<0.01, * * * P<0.001)$. 

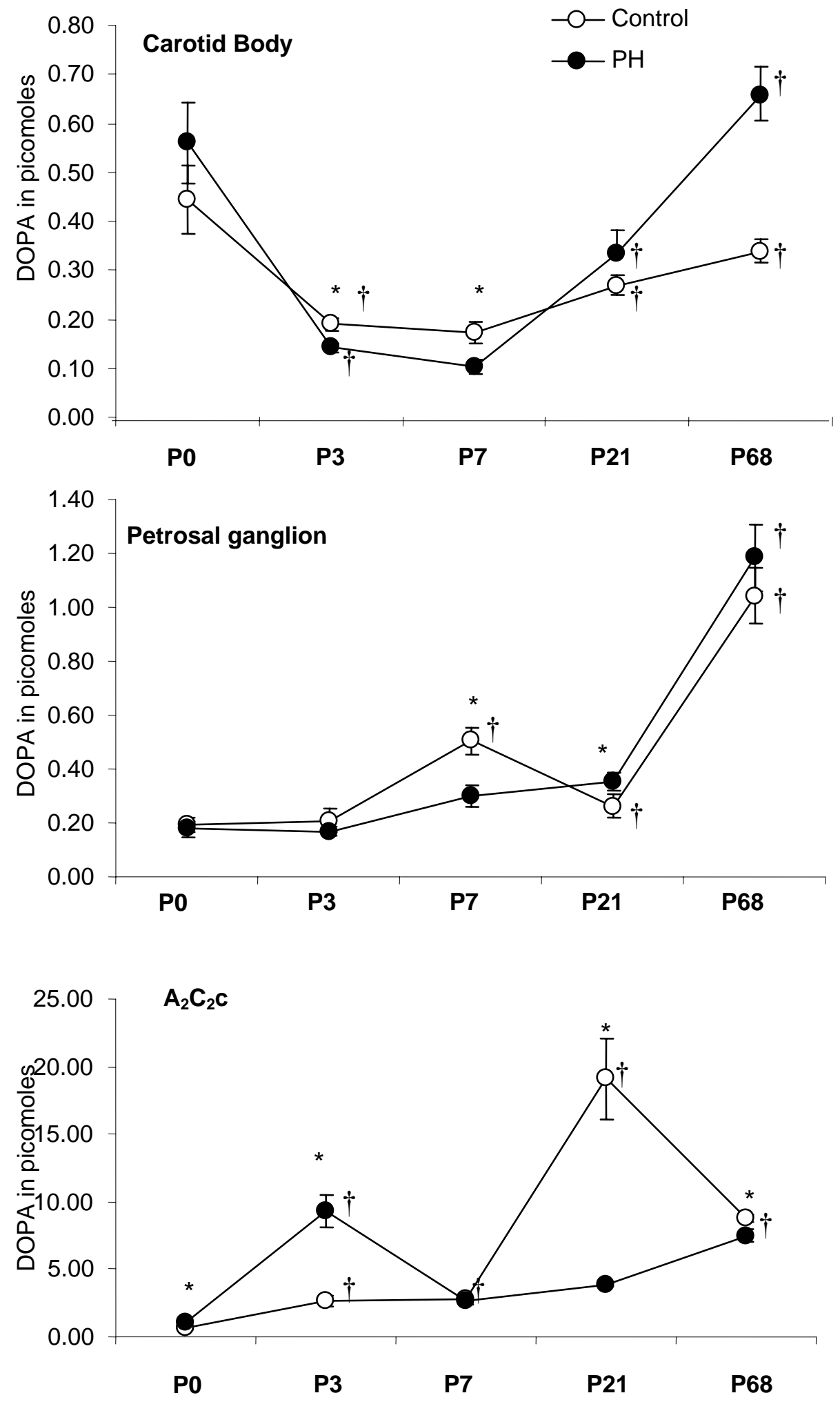

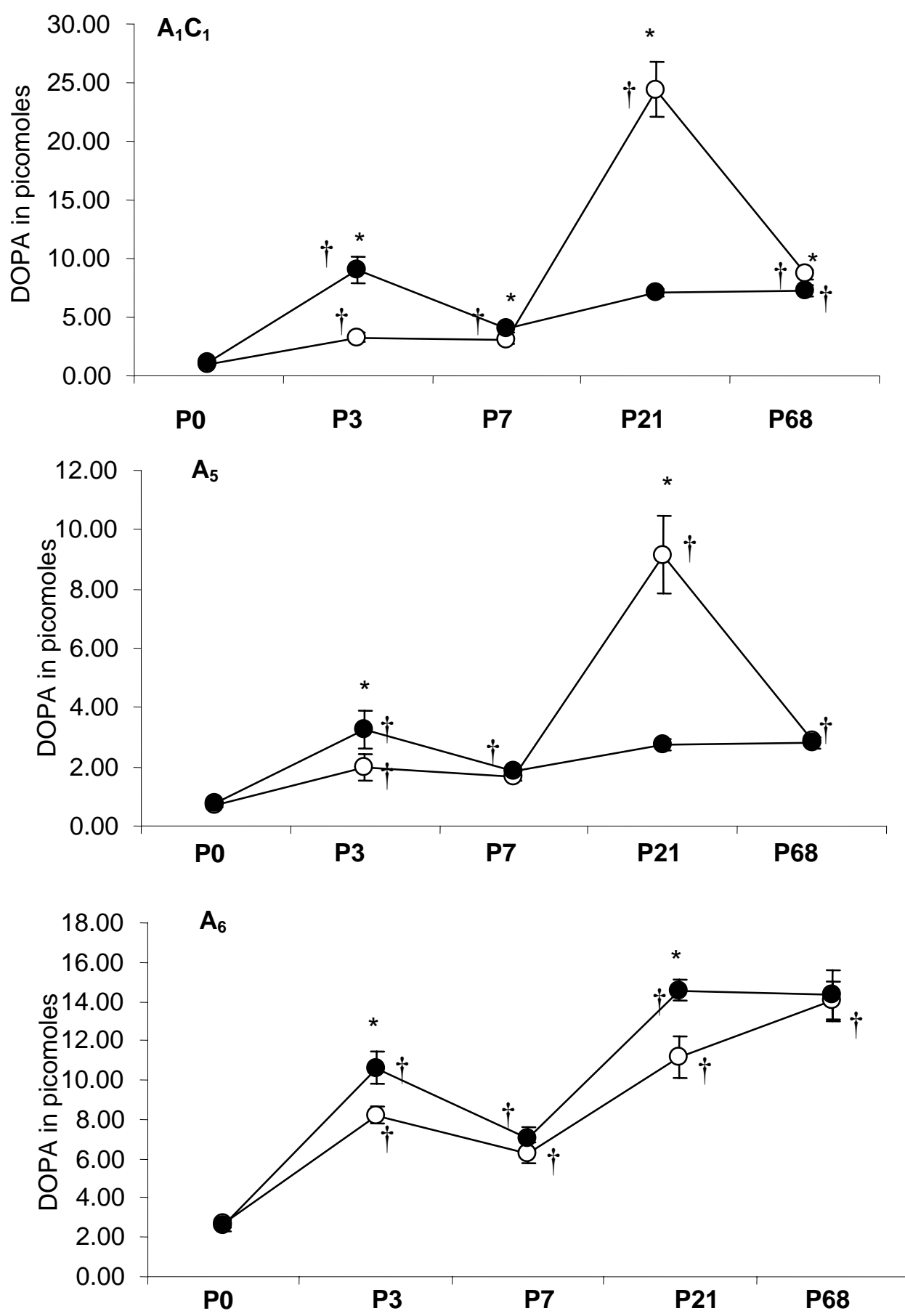

FIG.2. Effect of prenatal hypoxic exposure on the in vivo $\mathrm{TH}$ activity in the carotid body, petrosal ganglion and catecholaminergic medullary cell groups $\left(\mathrm{A}_{2} \mathrm{C}_{2} \mathrm{c}, \mathrm{A}_{1} \mathrm{C}_{1}, \mathrm{~A}_{5}\right.$ and $\mathrm{A}_{6}$ ) at birth (P0), postnatal days 3 (P3), 7 (P7), 21 (P21) and 68 (P68). Data are expressed as accumulation of picomoles of DOPA per 20 min per pair of cell groups $\left(\mathrm{A}_{1} \mathrm{C}_{1}, \mathrm{~A}_{2} \mathrm{C}_{2}, \mathrm{~A}_{5}, \mathrm{~A}_{6}\right)$ or per single peripheral structure (carotid body, petrosal ganglion) in control $(\circ)$ and in prenatal hypoxic $(\bullet)$ groups. ${ }^{*}$ statistically significant differences between control and age-matched prenatal hypoxic rats $(\boldsymbol{P}<\mathbf{0 . 0 5})$. $\dagger$ Statistically significant difference versus preceding group of age $(\boldsymbol{P}<\mathbf{0 . 0 5})$. 
PO

P3

P7

P21

P68

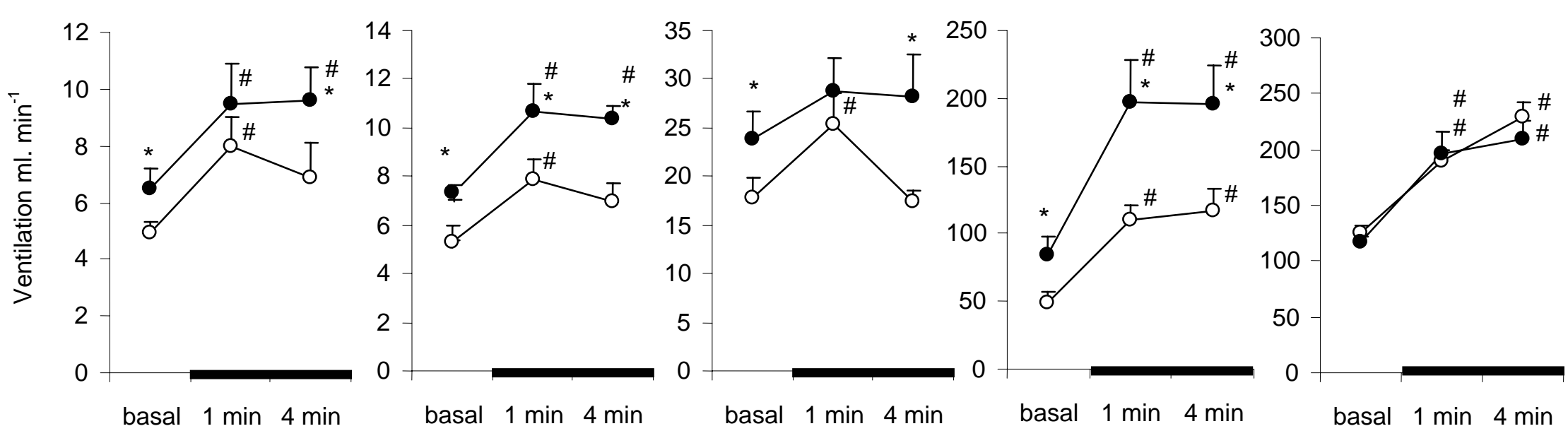

FIG.3. Effects of prenatal hypoxia on the postnatal maturation of the acute hypoxic ventilatory response. Each value represents the means \pm S.E.M. of minute ventilation $\left(\mathrm{ml}^{\mathrm{min}} \mathrm{m}^{-1}\right)$ in normoxia (basal) and in acute hypoxia after 1 and 4 min of exposure $\left(10 \% \mathrm{O}_{2}\right.$ and $\left.90 \% \mathrm{~N}_{2}\right)$. The ventilatory response is measured at birth (P0) and on postnatal days $3(\mathrm{P} 3), 7(\mathrm{P} 7), 21(\mathrm{P} 21)$ and $68(\mathrm{P} 68)$ in the control group (O) and in the prenatal hypoxic group $(\bullet)$. ${ }^{*}(\boldsymbol{P}<\mathbf{0 \cdot 0 5})$ Statistically significant differences between values of the control and the prenatal hypoxic groups; \# $(\boldsymbol{P}<\mathbf{0 \cdot 0 5})$ statistically significant differences between basal and hypoxic values in the control group or in the prenatal hypoxic group; $n=7-9$ rats in each group and at each age. 